\title{
TEMPERATURE DEPENDENCE OF BOUND EXCITON EMISSIONS IN GaN
}

\author{
D. G. Chtchekine, ${ }^{\text {a) }}$ G. D. Gilliland, ${ }^{\text {a) }}$ Z. C. Feng, ${ }^{\text {b), }}$ S. J. Chua, ${ }^{\text {b) }}$ D. J. Wolford, ${ }^{\text {c) }}$ \\ S. E. Ralph ${ }^{\text {d), }}$ M. J. Schurman, ${ }^{\text {e) }}$ and I. Ferguson ${ }^{\mathrm{e})}$ \\ ${ }^{a)}$ Physics Department, Emory University, Atlanta, GA 30322 \\ ${ }^{b}$ Institute of Material Research and Engineering, Singapore, 119260 \\ ${ }^{c}$ Physics Department and Microelectronics Research Center, Iowa State University, \\ Ames, IA 50011 \\ ${ }^{\mathrm{d})}$ School of Electrical and Computer Engineering, Georgia Institute of Technology, \\ Atlanta, GA 30332

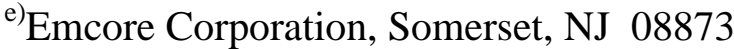 \\ $\dagger$ Work initiated when ZCF was with Emcore Corp. \\ ¥Work initiated when SER was with Emory University
}

Cite this article as: MRS J. Nitride Semicond. Res. 4S1, G6.47 (1999)

\begin{abstract}
The dissociation channels of two prominent bound exciton complexes in wurtzite GaN thin films are determined via an extensive temperature dependent photoluminescence study. The shallow donor bound exciton dissociation at low temperatures $(\mathrm{T} \leq 50 \mathrm{~K})$ is found to be dominated by the release of a free exciton with thermal activation energy consistent with the exciton localization energy. At higher temperatures a second dissociation channel with activation energy $\mathrm{E}_{\mathrm{A}}=28 \pm 2 \mathrm{meV}$ is observed. The dissociation of a bound exciton complex with exciton localization energy $\mathrm{E}_{\text {loc }}^{\mathrm{X}}=11.7 \mathrm{meV}$ is also dominated by the release of a free exciton. In contrast to previous studies evidence is presented against the hypothesis of this emission being due to the exciton bound to an ionized donor. We find that it originates most likely from an exciton bound to a neutral acceptor.
\end{abstract}

\section{INTRODUCTION}

Recent progress in the epitaxial growth of high quality GaN materials has permitted the observation of new photoluminescence (PL) emissions. Although some of these new transitions have been positively identified, ${ }^{1,2}$ broad PL linewidths preclude the definitive identification of other emissions. A bound exciton emission located $\sim 12 \mathrm{meV}$ below the free exciton is an example of such emission. This emission has been identified as a neutral acceptor-bound exciton $\left(\mathrm{A}^{0}, \mathrm{X}\right)^{3,4}$ or a neutral donor-bound exciton $\left(\mathrm{D}^{0}, \mathrm{X}\right)^{5}$ and more recently was assigned to an ionized donor-bound exciton $\left(\mathrm{D}^{+}, \mathrm{X}\right) \cdot 6,7$ The identification of the various emissions in $\mathrm{GaN}$ is essential to understanding and improving device performance via better dopants and more efficient luminescence.

The temperature dependence of the PL intensity of a bound exciton complex can be used to identify the kinetics of its thermal dissociation, and thus to provide a valuable insight into the origin of this complex. The main channel of thermal decay is the one with the least activation energy, $\mathrm{E}_{\mathrm{A}}$. In the case of a neutral donor-bound exciton complex in $\mathrm{GaN}$ the exciton delocalization from the neutral donor ( $\left.\mathrm{E}^{\mathrm{X}}{ }_{\text {loc }} \sim 6 \mathrm{meV}\right)$ is likely to be the minimum- 
energy dissociation channel of that complex. Temperature dependent photoluminescence studies have been employed previously to investigate neutral donor-bound exciton emissions in $\mathrm{GaN}$ and other materials. ${ }^{8-10}$ However, there exists some discrepancy in the reported values for the delocalization energy of the exciton bound to a neutral donor. The PL temperature study can be also used to clarify the origin of the bound exciton emission with $\mathrm{E}_{\text {loc }}^{\mathrm{X}}=11.7 \mathrm{meV}$, which we call $\mathrm{I}_{\mathrm{X}}$ emission. If this emission is due to the ionized donor-bound exciton complex the minimum-energy dissociation is expected to proceed through the break-off of a loosely bound hole, and thus the thermal activation energy equals the binding energy of the hole. On the other hand, if the $\mathrm{I}_{\mathrm{X}}$ emission originates from a neutral-impurity-center, the exciton delocalization is expected to be the lowest energy channel for thermal dissociation.

\section{EXPERIMENT}

We report on two lightly Si-doped GaN samples, each grown on (0001) sapphire with $\sim 20 \mathrm{~nm}$-thick GaN buffer by metalorganic chemical vapor deposition (MOCVD). Sample A has a GaN layer thickness of $3.3 \mu \mathrm{m}$ and was highly resistive. Sample B has an epilayer thickness of $2 \mu \mathrm{m}$ and a room temperature (RT) carrier concentration of $\mathrm{n} \cong 6.3 \times 10^{16} \mathrm{~cm}^{-3}$, as determined by Hall measurements.

PL spectra were obtained using the $325 \mathrm{~nm}$ line $(3.815 \mathrm{eV})$ of a cw He-Cd laser focused to $\sim 300 \mu \mathrm{m}$ diameter resulting in $\sim 0.5 \mathrm{~W} / \mathrm{cm}^{2}$ excitation power density. Samples were cooled to liquid-helium temperatures in a variable temperature $(1.5-300 \mathrm{~K})$ liquid-helium optical cryostat. The PL signal was dispersed by a $0.85-\mathrm{m}$ double spectrometer providing accuracy of $0.01 \mathrm{~nm}$, and detected by a cooled S-20 photomultiplier tube operating in photon-counting mode.

\section{RESULTS AND DISCUSSION}

Figure 1 shows the low temperature PL emissions from both samples. Free exciton (FE, $\mathrm{X})$ emissions are identified by their PL intensity being insensitive to the temperature compared to the bound exciton emissions $\left(D^{0}, X\right)$ and $I_{X}$ (see Figure 2). $\left(D^{0}, X\right)$ emission is identified by its well known spectral position $\sim 6 \mathrm{meV}$ below the A-band free exciton $\left(\mathrm{FE}_{\mathrm{A}}, \mathrm{X}\right)$.

Sample B shows a $\left(\mathrm{FE}_{\mathrm{A}}, \mathrm{X}\right)$ emission and a dominant $\left(\mathrm{D}^{0}, \mathrm{X}\right)$ emission originating from neutral Si donors. Sample A also exhibits these two emissions. However their absolute position is blue-shifted by $\sim 2.5 \mathrm{meV}$ in comparison with Sample B. This is likely due to the difference in the degree of the residual stress. Sample A also exhibits two additional emissions: a B-band free exciton $\left(\mathrm{FE}_{\mathrm{B}}, \mathrm{X}\right)$ (very weak in Sample $\mathrm{B}$ ) and a strong emission line labeled $\mathrm{I}_{\mathrm{X}}$ at $3.4735 \mathrm{eV}$, which is located at $11.7 \mathrm{meV}$ below the A-band free exciton line $\left(\mathrm{FE}_{\mathrm{A}}, \mathrm{X}\right)$. The $\mathrm{I}_{\mathrm{X}}$ emission is marked by a strong LO-phonon replica at $3.382 \mathrm{eV}$, indicating a strong electronphonon coupling. We determine an LO-phonon energy of $\hbar \omega_{\mathrm{LO}}=91.5 \mathrm{meV}$, consistent with the literature. ${ }^{11}$ In Sample A the first excited state ( $2 S$ state) of the A-band exciton is observed at $3.5035 \mathrm{eV}$, as also shown on Figure 1. The positive identification of this emission was confirmed by a magneto-spectroscopy study which will be published elsewhere. From the energy separation between $1 S$ and $2 S$ states we can determine the free exciton binding energy in the Coulomb potential approximation: $\mathrm{E}_{\mathrm{b}}^{\mathrm{X}}=4 / 3 \times\left(\mathrm{E}_{2 S}-\mathrm{E}_{1 S}\right)=24.4 \pm 0.5 \mathrm{meV}$, consistent with other reports. ${ }^{2}$

To assess the temperature variation of the integrated intensity of the $\left(\mathrm{D}^{0}, \mathrm{X}\right)$ and $\mathrm{I}_{\mathrm{X}}$ emissions all strong near-bandedge lines have been fitted with Gaussian lineshapes (see Figure 1). The low-energy tails of the $\left(\mathrm{D}^{0}, \mathrm{X}\right)$ and $\mathrm{I}_{\mathrm{X}}$ emissions were disregarded during fitting; 


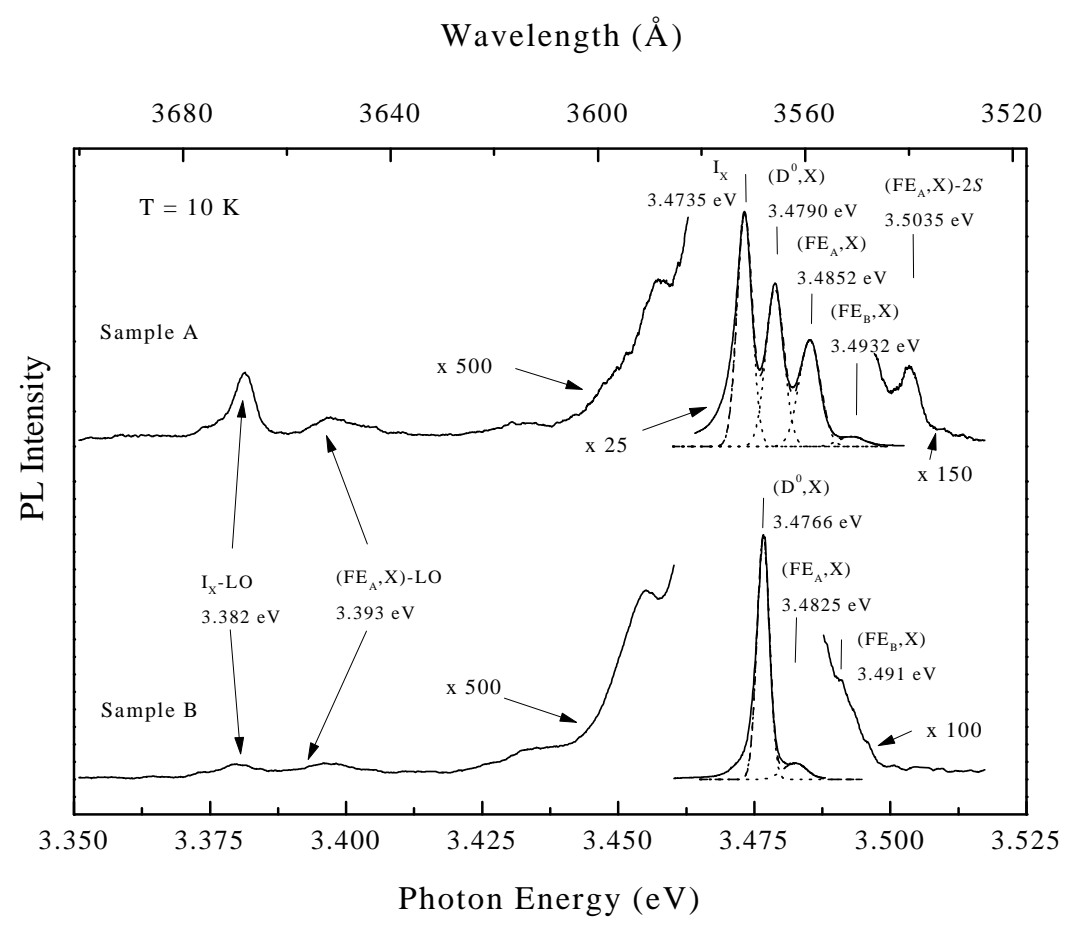

Figure 1. Low-temperature PL spectra of Samples A and B. Sample A is marked by a strong emission $I_{X}$ at $3.473 \mathrm{eV}$. Dashed lines represent the fit with gaussian lineshapes (dotted lines). Strong LO-phonon replica of the $I_{X}$ emission is observed at $3.382 \mathrm{eV}$. Transition at $3.5035 \mathrm{eV}$ is due to the first excited state of the A-band free exciton.

importantly this does not change the character of their temperature dependence. A two-channel dissociation Arrhenius model was used to fit the temperature dependence of the PL integrated intensity of the $\left(\mathrm{D}^{0}, \mathrm{X}\right)$ emission in Sample B:

$$
\frac{I(T)}{I(0)}=\frac{1}{1+C_{1} \times \exp \left(-\frac{E_{1 A}}{k T}\right)+C_{2} \times \exp \left(-\frac{E_{2 A}}{k T}\right)}
$$

where $\mathrm{I}(\mathrm{T})$ and $\mathrm{I}(0)$ are the integrated intensities of the $\left(\mathrm{D}^{0}, \mathrm{X}\right)$ emission at temperature $\mathrm{T}$ and 0 $\mathrm{K}$, respectively, $\mathrm{E}_{1 \mathrm{~A}}$ and $\mathrm{E}_{2 \mathrm{~A}}$ are activation energies and $\mathrm{C}_{1}, \mathrm{C}_{2}$ are constants.

The temperature dependence of $\mathrm{I}_{\mathrm{X}}$ emission was analyzed using a single-channel dissociation Arrhenius model:

$$
\frac{I(T)}{I(0)}=\frac{1}{1+C \times \exp \left(-\frac{E_{A}}{k T}\right)}
$$

Figure 2 shows the temperature dependence of the integrated intensity of the $\left(\mathrm{FE}_{\mathrm{A}}, \mathrm{X}\right)$, $\left(\mathrm{D}^{0}, \mathrm{X}\right)$ and $\mathrm{I}_{\mathrm{X}}$ emissions, together with the results of the fitting. As shown, the temperature dependence of the $\left(\mathrm{D}^{0}, \mathrm{X}\right)$ emission in Sample $\mathrm{B}$ is well described with the two-channel dissociation model of Eq. (1). We obtain activation energies $E_{1 \mathrm{~A}}=5.9 \pm 0.2 \mathrm{meV}$ and $\mathrm{E}_{2 \mathrm{~A}}=28$ 
$\pm 2 \mathrm{meV}$. The activation energy $\mathrm{E}_{1 \mathrm{~A}}$ is in excellent agreement with the energy of exciton localization on a shallow donor $\mathrm{E}^{\mathrm{X}}{ }_{\text {loc }}=6.2 \pm 0.4 \mathrm{meV}$ (see Figure 1). The temperature dependence of the $\left(\mathrm{D}^{0}, \mathrm{X}\right)$ emission in Sample A (fitted with a single-channel dissociation model due to a limited temperature range) exhibits thermal activation energy $\mathrm{E}_{\mathrm{A}}=5.6 \pm 0.3$ $\mathrm{meV}$, which is also in a very good agreement with the exciton localization energy and the value of $E_{1 \mathrm{~A}}$ in Sample B. Therefore, we conclude that the dominant channel of thermal dissociation

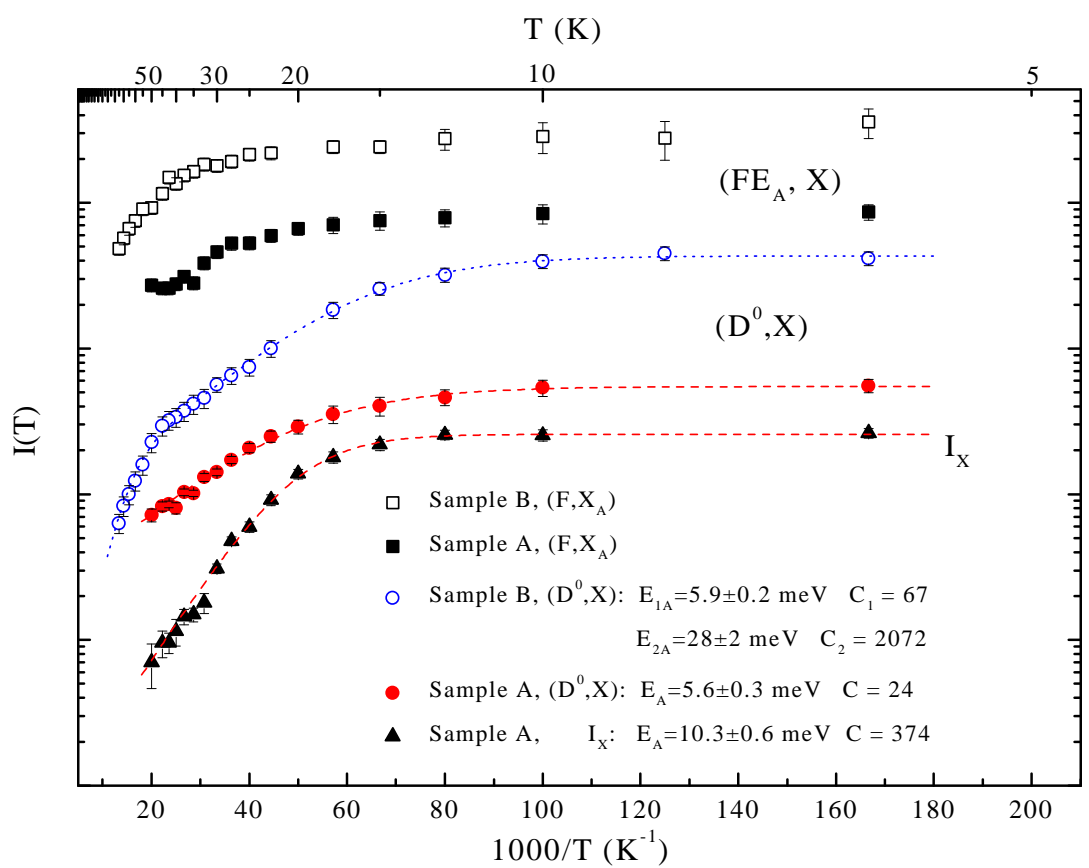

Figure 2. Temperature dependence of the integrated $P L$ intensity of $\left(F E_{A}, X\right)$ emission (Samples $A$ and $B),\left(D^{O}, X\right)$ emission (Samples $A$ and $\left.B\right)$, and $I_{X}$ emission (Sample A). The plots are vertically displaced for the convenience of viewing. Dotted and dashed lines represent fits with Eq. (1) and Eq (2), respectively.

for the $\left(\mathrm{D}^{0}, \mathrm{X}\right)$ complex at low temperatures $(\mathrm{T} \leq 50 \mathrm{~K})$ is the release of a free exciton.

At higher temperatures another thermal dissociation channel with activation energy $\mathrm{E}_{2 \mathrm{~A}}$ $\cong 28 \mathrm{meV}$ is clearly observed (see Figure 2). The second dissociation channel may be due to the decay of the $\left(\mathrm{D}^{0}, \mathrm{X}\right)$ complex via simultaneous exciton delocalization and exciton dissociation with activation energy $\mathrm{E}_{2 \mathrm{~A}} \cong \mathrm{E}_{\mathrm{b}}^{\mathrm{X}}+\mathrm{E}^{\mathrm{X}}{ }_{\text {loc }} \cong 30 \mathrm{meV} .{ }^{12}$ Alternatively, a neutral donor ionization process, with activation energy $\mathrm{E}_{2 \mathrm{~A}}=\mathrm{E}_{\mathrm{D}} \cong 29 \mathrm{meV}, 13$ may also affect the PL intensity of the $\left(\mathrm{D}^{0}, \mathrm{X}\right)$ emission, since it reduces the number of the neutral-donor centers to which photo-excited excitons can bind to form the $\left(\mathrm{D}^{0}, \mathrm{X}\right)$ complexes. ${ }^{8}$ A detailed study of exciton kinetics is required to determine which of these two channels governs the temperature dependence of the $\left(\mathrm{D}^{0}, \mathrm{X}\right)$ emission at higher temperatures.

The temperature dependence of the $\mathrm{I}_{\mathrm{X}}$ emission is well fit by Eq. (2) in the experimental temperature range, resulting in $\mathrm{E}_{\mathrm{A}}=10.7 \pm 0.6 \mathrm{meV}$. This activation energy is very close to the exciton localization energy of the $\mathrm{I}_{\mathrm{X}}$ complex: $\mathrm{E}^{\mathrm{X}}{ }_{\mathrm{loc}}=11.7 \mathrm{meV}$. This indicates that the $\mathrm{I}_{\mathrm{X}}$ bound exciton complex dissociates by releasing a free exciton, similar to the $\left(\mathrm{D}^{0}, \mathrm{X}\right)$ complex.

It has been suggested that the $\mathrm{I}_{\mathrm{X}}$ emission is due to the exciton bound to the ionized 
donor. 6,7 The $\left(\mathrm{D}^{+}, \mathrm{X}\right)$ complex is more stable in systems with a smaller ratio of the electron and hole effective mass $\sigma=\mathrm{m}_{\mathrm{e}} / \mathrm{m}_{\mathrm{h}} \cdot{ }^{14}$ Maintaining the hole bound to the donor is the weak link in the stability of the $\left(\mathrm{D}^{+}, \mathrm{X}\right)$ complex. A somewhat similar situation was reported in $\mathrm{GaP}^{15}$ where the thermal release of the hole was favored over the exciton delocalization for isoelectronic traps.

We can estimate the binding energy of the hole in the current system by evaluating the electron-hole mass ratio, $\sigma$. From the value of the free exciton binding energy the exciton reduced mass can be estimated to be $\mu^{*}=\left(\mathrm{m}^{\mathrm{p}}{ }_{\mathrm{e}} \cdot \mathrm{m}_{\mathrm{h}}^{\mathrm{p}}\right) /\left(\mathrm{m}_{\mathrm{e}}^{\mathrm{p}}+\mathrm{m}_{\mathrm{h}}^{\mathrm{p}}\right)=0.162$. Here all masses are taken to be polaron masses due to the strong electron-phonon interaction in GaN. Taking the electron polaron mass $\mathrm{m}_{\mathrm{e}}^{\mathrm{p}}=0.22^{16}$, we find the hole polaron mass $\mathrm{m}_{\mathrm{h}}^{\mathrm{p}}=0.61$ and $\sigma^{\mathrm{p}}=0.36$. Since the value of $\sigma^{\mathrm{p}}$ is smaller than $\sigma_{\text {crit. }}=0.43,{ }^{14}$ the $\left(\mathrm{D}^{+}, \mathrm{X}\right)$ complex is theoretically allowed in $\mathrm{GaN}$. The hole binding energy can be now estimated in the approximation of the Coulomb potential using the Figure 1 of Skettrup et al.. ${ }^{14}$ To find an upper limit for the hole binding energy we take a value of the electron-hole mass ratio: $\sigma=0.3$, which is more favorable for the existence of the $\left(D^{+}, X\right)$ complex. Let's denote a neutral donor energy level $E_{D}\left(E_{D}=29\right.$ $\left.\mathrm{meV}^{13}\right)$ and ionized donor-bound exciton energy level $\mathrm{E}_{\left(\mathrm{D}^{+}, \mathrm{X}\right)}$. Then from the Figure 1 of Skettrup we obtain $\left(\mathrm{E}_{\left(\mathrm{D}^{+}, \mathrm{X}\right)}-\mathrm{E}_{\mathrm{D}}\right) / \mathrm{E}_{\mathrm{D}} \cong 1 \%$ which yields a hole binding energy of $\left.\mathrm{E}_{\mathrm{h}}=\mathrm{E}_{(\mathrm{D}}{ }^{+}, \mathrm{X}\right)^{-}$ $\mathrm{E}_{\mathrm{D}} \cong 0.3 \mathrm{meV}$. Since the distance between hole and donor can be estimated ${ }^{14}$ at $\sim 120 \AA$ for $\sigma=$ 0.3 and the sum of the polaron radii for electron and hole is $\sim 20 \AA$ in $\mathrm{GaN}$, the electron-phonon interaction is not expected to affect the hole binding energy significantly. We may, therefore, conclude that the thermal dissociation of the $\left(\mathrm{D}^{+}, \mathrm{X}\right)$ complex in $\mathrm{GaN}$ proceeds via the release of a free hole, with very small activation energy $E_{A} \leq 1 \mathrm{meV}$, which should make the observation of this complex possible only at very low temperatures.

The results of Figure 2 for the $\mathrm{I}_{\mathrm{X}}$ emission do not exhibit $\mathrm{E}_{\mathrm{A}} \cong 1 \mathrm{meV}$; indeed we determine $\mathrm{E}_{\mathrm{A}}=10.7 \mathrm{meV}$. It is therefore very unlikely that $\mathrm{I}_{\mathrm{X}}$ emission originates from a $\left(\mathrm{D}^{+}, \mathrm{X}\right)$ complex. Since $\mathrm{E}_{\mathrm{A}} \cong \mathrm{E}^{\mathrm{X}}{ }_{\mathrm{loc}}=11.7 \mathrm{meV}$ the main channel of dissociation for the $\mathrm{I}_{\mathrm{X}}$ emission should be release of a free exciton, which is consistent with the neutral impuritybound exciton model. Since the $\mathrm{I}_{\mathrm{X}}$ emission indicates a strong coupling to LO-phonons, contrasting the $\left(\mathrm{D}^{0}, \mathrm{X}\right)$ emission in our samples, we believe that it originates from a neutral acceptor-bound exciton. This hypothesis is also consistent with the fact that strong $\mathrm{I}_{\mathrm{X}}$ emission is observed only in highly compensated samples. We can estimate the binding energy of this acceptor using Haynes' rule which has been shown to be valid for acceptors in GaN17: $E_{b}=$ $\mathrm{E}^{\mathrm{X}}{ }_{\text {loc }} / 0.1=120 \mathrm{meV}$. Therefore the free-to-bound $\left(\mathrm{e}, \mathrm{A}^{0}\right)$ transition involving this shallow acceptor can be, in principle, observed around $3.390 \mathrm{eV}$. Unfortunately the observation of (e, $\mathrm{A}^{0}$ ) emission is likely to be masked by the strong LO-phonon replica of the $\left(\mathrm{FE}_{\mathrm{A}}, \mathrm{X}\right)$ emission at $3.393 \mathrm{eV}$. The existence of such a shallow acceptor $\left(\mathrm{E}_{\mathrm{b}}=120 \mathrm{meV}\right)$ in $\mathrm{GaN}$ would be significant since it would provide a more effective $p$-type dopant.

\section{CONCLUSIONS}

In summary, our temperature study of the shallow bound exciton emissions in GaN shows that the activation energy of thermal dissociation of the $\left(D^{0}, X\right)$ complex at low temperatures $(\mathrm{T} \leq 50 \mathrm{~K})$ is in good agreement with the exciton localization energy, thereby proving that at low temperatures the main dissociation channel of shallow bound exciton complexes in $\mathrm{GaN}$ is the release of a free exciton. At higher temperatures a second dissociation channel is clearly observed, which may be due to the process of simultaneous exciton delocalization and dissociation and/or neutral donor ionization. An analysis of the thermal 
stability of the ionized donor-bound exciton leads to the conclusion that the least-energy thermal decay of this complex should proceed via the release of a free hole, with a very small activation energy $E_{A} \leq 1 \mathrm{meV}$. This contradicts the results of our temperature study for the bound exciton emission with $\mathrm{E}_{\text {loc }}^{\mathrm{x}}=11.7 \mathrm{meV}$, for which we find the thermal activation energy $\mathrm{E}_{\mathrm{A}}=10.7 \mathrm{meV}$. Therefore, the assumption of this emission being due to the exciton bound to an ionized donor is not valid. Since the thermal activation energy and localization energy are in good agreement for this emission, similarly to the case of the $\left(\mathrm{D}^{0}, \mathrm{X}\right)$ emission, we conclude that it originates from an exciton bound to a neutral impurity - most likely a neutral acceptor.

\section{REFERENCES}

1 B. J. Skromme, H. Zhao, B. Goldenberg, H. S. Kong, M. T. Leonard, G. E. Bulman, C. R. Abernathy, and S. J. Pearton, in III-V Nitrides, edited by F. A. Ponce, T. D. Moustakas, I. Akasaki, and B. A. Monemar ( Mater. Res. Soc. Symp. Proc. 449, Pittsburgh, 1997) p. 713.

2 D. Volm, K. Oettinger, T. Streibl, D. Kovalev, M. Ben-Chorin, J. Diener, B. K. Meyer, J. Majewski, L. Eckey, A. Hoffmann, H. Amano, I. Akasaki, K. Hiramatsu, and T. Detchprohm, Phys. Rev B 53, 16543 (1996).

3 Y. Kawakami, Z. G. Peng, Y. Narukawa, S. Fujita, S. Fujita, and S. Nakamura, Appl. Phys. Lett. 69, 1414 (1996).

$4 \quad$ K. Pakula, A. Wysmolek, K. P. Korona, J. M. Baranowski, R. Stepniewski, I. Grzegory, M. Bockowski, J. Jun, S. Krukowski, M. Wroblewski, and S. Porowski, Solid State Commun. 97, 919 (1996).

5 S. Fischer, D. Volm, D. Kovalev, B. Averboukh, A. Graber, H. C. Alt, and B. K. Meyer, Mater. Sci. Eng. B 43, 192 (1997).

6 D. C. Reynolds, D. C. Look, B. Jogai, V. M. Phanse, and R. P. Vaudo, Solid State Commun. 103, 533 (1997).

7 B. Santic, C. Merz, U. Kaufmann, R. Niebuhr, H. Obloh, and K. Bachem, Appl. Phys. Lett. 71, 1837 (1997).

8 B. K. Meyer, in III-V Nitrides, edited by F. A. Ponce, T. D. Moustakas, I. Akasaki, and B. A. Monemar (Mater. Res. Soc. Symp. Proc. 449, Pittsburgh, 1997) p. 497.

9 G. D. Chen, M. Smith, J. Y. Lin, H. X. Jiang, M. A. Khan, and C. J. Sun, Appl. Phys. Lett. 67, 1653 (1995).

10 G. D. Gilliland, Mater. Sci. Eng. R 18, 141 (1997).

11 T. Kozawa, T. Kachi, H. Kano, Y. Taga, M. Hashimoto, N. Koide, and K. Manabe, J. Appl. Phys. 75, 1098 (1994).

12 P. J. Dean, Phys. Rev. 157, 655 (1967).

13 Y. J. Wang, R. Kaplan, H. K. Ng, K. Doverspike, D. K. Gaskill, T. Ikedo, I. Akasaki, and H. Amano, J. Appl. Phys. 79, 8007 (1996).

14 T. Skettrup, M. Suffczynski, and W. Gorzkowski, Phys. Rev. B 4, 512 (1971).

15 M. D. Sturge, E. Cohen, and K. F. Rodgers, Phys. Rev. B 15, 3169 (1977).

16 H. C. Alt, B. K. Meyer, D. Volm, A. Graber, M. Drechsler, D. M. Hofmann, T. Detchprohm, A. Amano, and I. Akasaki, Mater. Sci. Forum 196, 17 (1995).

17 C. Merz, M. Kunzer, U. Kaufmann, I. Akasaki, and H. Amano, Semicond. Sci. Technol. 11, 712 (1996). 